\title{
Cardiopulmonary resuscitation
}

Series editors: P D MacIntyre, W S Hillis

\section{Basic life support}

The term basic life support (BLS) means maintaining an airway and supporting breathing and circulation without the use of equipment (except for a protective shield). It consists of: (a) initial assessment; (b) airway maintenance; (c) expired air ventilation; $(d)$ chest compression.

Three quarters of all cardiac arrests occur out of hospital, and, when witnessed, up to $30 \%$ of patients who suffer out of hospital ventricular fibrillation arrests survive to leave hospital. Bystander initiated life support can double the number of people who survive the period before hospital admission. BLS skills once learned must be maintained.

The European guidelines describe a "sequence of actions"

- Ensure safety of rescuer and patient

- Check patient and see if he/she responds

- Gently shake his/her shoulders and ask loudly: "are you all right?"

- If the patient responds by answering or moving

- Leave him/her in the position in which you found him/her (provided that he/she is not in further danger), check his/her condition, and seek help if needed

- Make regular reassessments

- If he/she does not respond

- Shout for help.

\section{Open the Airway}

- Tilt the head back and lift the chin

- Remove any obstruction from the mouth; leave dentures in place unless loose

\section{Look, listen, and feel for Breathing (for up to 10} seconds)

- Look for chest movements

- Listen at the mouth for breath sounds

- Feel for expired air on your cheek

If the patient is breathing

- Turn him/her to the recovery position (unless contraindicated), telephone 999 for help, and continue to check for continued breathing

If the patient is not breathing

- Send someone for help (999) or if alone go for help

- On return, turn the patient on to his/her back and give two effective rescue breaths sufficient to produce a rise and fall in the chest. A maximum of five attempts only should be made to provide these two rescue breaths.

\section{Assess the Circulation}

Check the carotid pulse (for up to 10 seconds)

If present, continue ventilation at about 10 breaths per minute and reassess every minute for continuing circulation. If spontaneous breathing occurs, turn the patient into the recovery position but continue monitoring.

If circulation is absent (or if you are unsure)

- Start external chest compression; the appropriate pressure should depress the sternum between 4 and 5

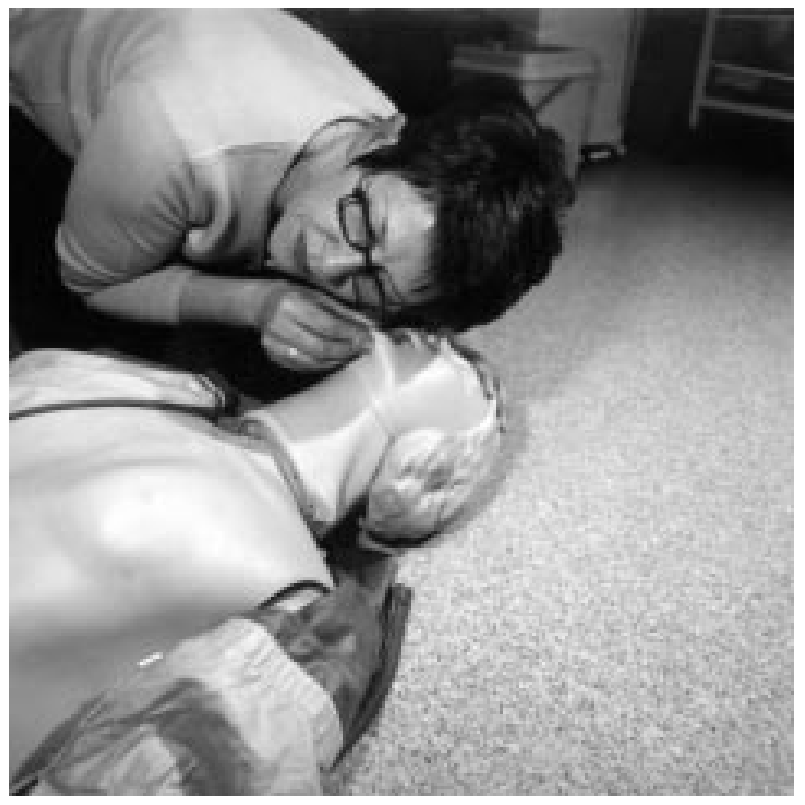

Look for breathing

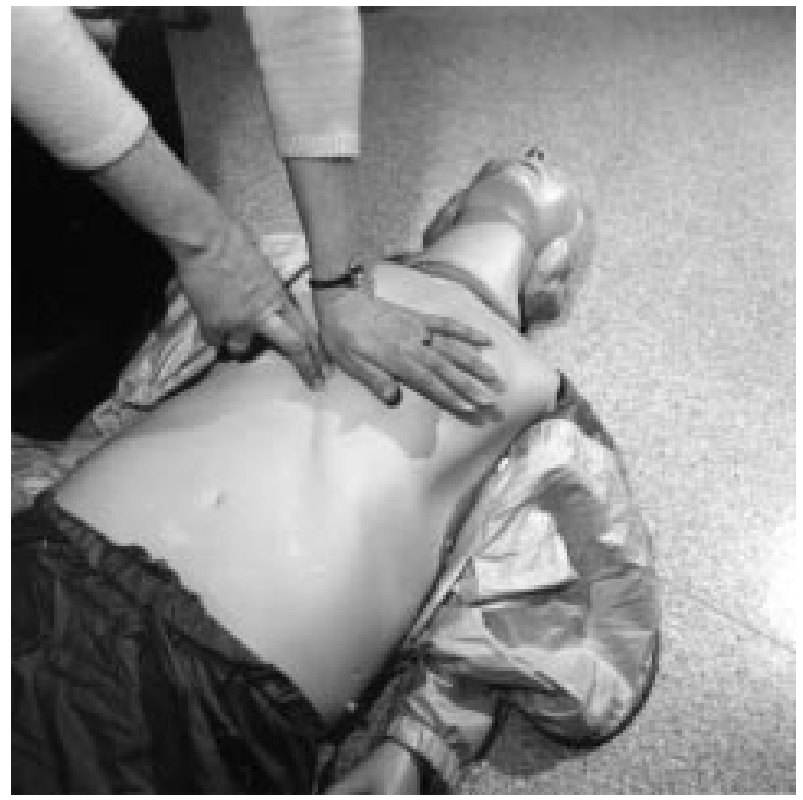

Positioning of hands

$\mathrm{cm}$ at a rate of about 100 times per minute, with compression and release taking an equal amount of time.

- Combine chest compression and rescue breathing at a ratio of 15 to 2

- Continue resuscitation until the patient shows signs of life or qualified help arrives or you become exhausted 


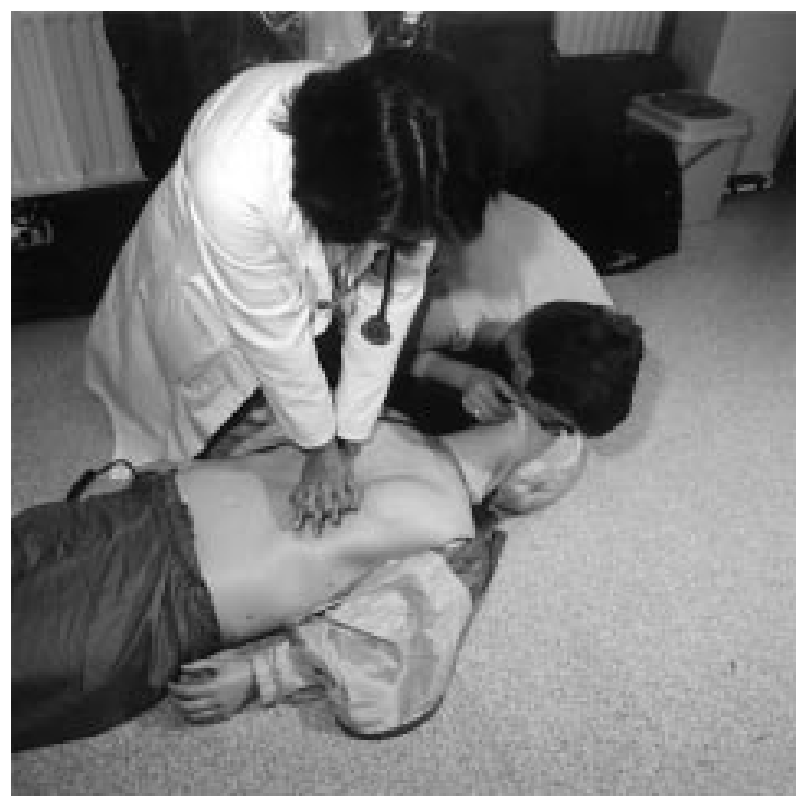

External chest compression

BLS should not be interrupted for a carotid pulse check. Continued lack of obvious signs of life is sufficient indication to continue BLS. It is vital to obtain help as soon as possible with a view to instituting defibrillation and advanced life support to result in recovery of the patient. Although the timing of when to obtain help may be influenced by clinical and practical factors, in general it is advisable to go for help immediately if it is established that the patient is not breathing. Possible exceptions are if the likely cause is trauma or drowning, or the patient is a child (in children respiratory arrest is more common than cardiac arrest), in which case resuscitation should be performed for one minute before help is sought. When two rescuers are present, one should start with BLS while the other looks for help. On return of the latter, the two rescuers should work on opposite sides of the patient and continue with BLS, with a ratio of five compressions to one inflation.

J A MCLEAN

Clinical Lecturer

Department of Medicine and Therapeutics

University of Glasgow

Gardiner Institute

Western Infirmary

Glasgow G11 6NT

United Kingdom

\section{Further reading}

Graham CA, Scollop D, McGowan J, Gordon MW. Resuscitation. 1. Basic life support. [[Review; 10 refs]] Br f Hosp Med 1997;58:15-18.

Wraith A. New resuscitation guidelines. European Research Council. SAAD Digest 1997;14:14-18.

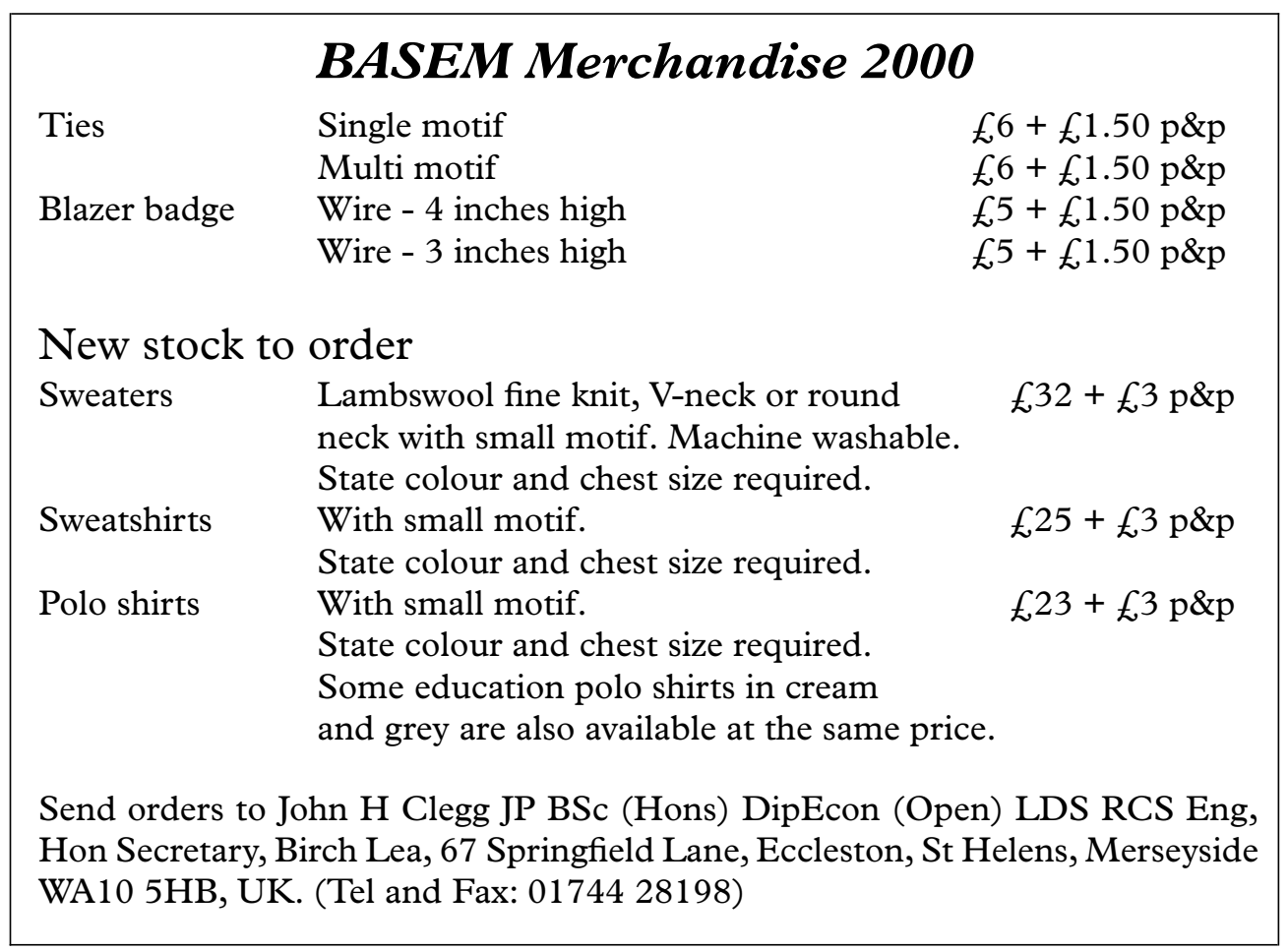

